\title{
Scenario-Based Allocation of Emergency Resources in Metro Emergencies: A Model Development and a Case Study of Nanjing Metro
}

\author{
Ying $L u^{*}$ and Shuqi Sun \\ School of Civil Engineering, Southeast University, Nanjing 211189, China; 220191157@seu.edu.cn \\ * Correspondence: luying_happy@126.com; Tel.: +86-13913912982
}

Received: 2 July 2020; Accepted: 6 August 2020; Published: 7 August 2020

check for updates

\begin{abstract}
As metro systems are becoming more and more widely used, all kinds of emergencies happen from time to time. A series of cases indicate that inefficient emergency response is a dominating cause of tremendous casualties and losses. The fast and valid allocation of emergency resources after the occurrence of metro emergencies has become a key point in improving the sustainability of metro operations. However, few studies have attempted to determine the allocation of emergency resources in metro emergencies. In this study, considering the unpredictability of different emergency scenarios in the metro system, the scenario-response mode was applied in the resource allocation decision. In this mode, a metro emergency scenario framework was first constructed through the identification of metro emergency elements. Next, a multi-objective model was established for the allocation of emergency resources in the metro emergency rescue process using a scenario-based analysis. The model aims to minimize both the penalty costs due to delays and the sum of allocation costs. The particle swarm optimization algorithm was adopted to solve the model. Eventually, a fire accident scenario at Nanjing Metro was applied to verify the feasibility and validity of the presented model and algorithm. The research results not only enrich and improve metro emergency management theoretically, but also enhance metro emergency rescue ability in practice.
\end{abstract}

Keywords: metro emergency; emergency resource allocation; scenario analysis; particle swarm optimization

\section{Introduction}

As an increasingly important vehicle in the city, metro is becoming one of the paramount symbols of a city's development and prosperity. In 1863, the world's first metro system was opened to the public in London. Subsequently, extensive metro transit networks were constructed in major cities all over the world [1]. As of 2018, metro lines had spread across 179 cities, with a total length of 14,219.36 km and more than 10,631 stations [2]. However, accidents occur during the operation of metro systems from time to time, hindering the sustainable development of society. For instance, a Moscow metro came to a screeching halt and derailed after receiving an incorrect signal in 2014, leaving 23 people killed and 160 injured. In 2016, a fire broke out at Ginza station of the Tokyo Metro during morning rush hours, causing the stagnation of 68,000 people. The variety of emergencies that have occurred shows that the accident rate of metro systems is high, and the harm that occurs is enormous due to the complexity of metro systems and the characteristics of their running circumstances.

Recently, emergency management has caused widespread concern, of which the emergency management of metro operation has become an urgent problem to be solved [3]. The effective disposal of metro emergencies is becoming increasingly important for the resilience of metro operation and thus further promotes social and economic sustainability. One of the pivotal issues of metro emergency management is emergency resource allocation [4]. Metro emergency resources are the 
basis and guarantee of metro emergency rescue. The contingency plans for urban rail transit operation emergencies issued by the State Council and each city of China all clarify the importance of emergency resources in emergency rescue [5]. The plans point out that the Government and operation department should strengthen the reserve of emergency equipment and resources as well as the dynamic management of resource information. Emergency resource allocation is the process of mobilizing all kinds of resources needed in an emergency [6]. Reasonable allocation of emergency resources can effectively mitigate casualties and property losses and improve the efficiency and economy of rescue work [7-9]. It is necessary to store and allocate emergency resources inside the metro system, not just rely on external rescue forces. Therefore, the construction of micro rescue stations in metros is the first force to respond to emergencies quickly and effectively. Metro staff can use micro rescue stations to improve the allocation efficiency of emergency resources. For example, since 1 January 2016, a total of 359 micro fire stations have been set up in the Beijing metro system, and 7000 staff have been deployed [10]. Fume extractors, smoke masks, air respirators, and other emergency resources were pre-positioned in the rescue stations in advance for allocation and use.

However, most metro emergency resource allocations are mainly based on previous experience and lack scientific theoretical guidance, which is defective. There are still many deficiencies in the system, such as the lack of plan for the resources or contradictions between supply and demand. For example, a heavy rain paralyzed the New York metro system in 2007. Lagging maintenance and deficient emergency resources plunged the whole city into chaos. The New York Metropolitan Transportation Authority (MTA), which manages public transportation in New York City, apologized to the public for failing to address the breakdown of the metro system. In 2003, an arson accident broke out in Daegu metro station in South Korea. Even though it was only a two-minute walk from the accident site to the exit, 140 people were killed and 289 injured. The main reason was the serious shortage of automatic sprinkler equipment, smoke removal equipment, and emergency searchlights. The negative allocation of resources seriously hindered the rescue operation and increased the number of casualties [11]. Therefore, it is quite necessary to study the efficient allocation of emergency resources in metro emergencies.

For a long time, emergency management has mainly adopted the forecast-response mode, that is, emergency plans are made in advance according to the forecast of possible emergencies [12]. The shortcoming of this mode is that it cannot adapt to the scenarios randomly, which leads to poor performance of emergency management. Metro emergencies are sudden and unpredictable, and are difficult to predict relying on subjective experience [13]. Therefore, it is necessary to quickly identify and analyze the real-time information of emergencies by fully understanding their structure, evolution, and mechanism, so as to make timely and effective countermeasures [14]. As a result, the scenario-response mode is gaining popularity in emergency management. The application of the scenario-response mode in the allocation of metro emergency resources is meaningful.

Following this introduction, the rest of this paper is set out as follows. Related works are reviewed in Section 2. The application of scenario analysis in metro emergency resource allocation is described in Section 3. Section 4 is devoted to describing the methodology in this study, including scenario-based model development and model solving algorithm. A multi-objective allocation model was established based upon a profound scenario analysis of metro emergencies. A detailed description of the calculation process for the particle swarm optimization algorithm is also provided in this section. In Section 5, results of a typical fire scenario based on the Nanjing metro network system illustrate the feasibility and validity of the proposed model and algorithm. The sensitivity of the objective function is analyzed as well. Finally, the conclusions and discussions are presented in Section 6. 


\section{Literature Review}

\subsection{Metro Emergency Management}

There has been a certain amount of research in the area of metro emergency management. Existing studies can be divided into three aspects: Metro emergency evacuation studies, metro emergency response process, and site selection of rescue facilities. Firstly, metro emergency evacuation has achieved universal attention of many scholars in recent years [15]. There are three existing evacuation simulation models: Discrete, continuous, and multi-agent [16,17]. The optimization of evacuation routes is another direction. Research found that typical evacuation strategies have been adopted by metro passengers in accidents, for example, ripple evacuation, shortest-path evacuation, herd evacuation, and so on [18]. Furthermore, factors affecting evacuation have also received attention, such as automatic ticket checkers, stair width, walking speed, and so on $[19,20]$. Secondly, the emergency response process is a research hotspot for metro emergency management, mainly focusing on the detection of underlying conflicts in metro emergency response process with respect to time, order, and resources [6]. Modeling methods for the metro emergency response process have also been studied. Thirdly, rescue facility location is essentially a geospatial multi-objective optimization problem [21]. Most research has considered time and cost as the main optimization objectives. The genetic algorithm, heuristic method, NSGA-II algorithm, and algorithms integrated with geographic information system (GIS) were proposed for solving the problems [22-25]. Metro emergency resource allocation schemes play an important role in metro emergency management, but there have been few studies on it. The improvement of resource allocation performance in a more predictive manner, for instance, planning specific deployment with computational tools, is still lacking.

\subsection{The Allocation of Emergency Resources}

Several scholars have carried out research on the allocation of emergency resources. The initial stage of research was about the allocation of emergency service vehicles. Kolesar and Walker studied the problem of vehicle configuration in the field of city fire protection [26]. With the deepening of exploration, research flourished. The study of emergency resource allocation has slowly extended into the field of natural disasters [27-30], hazardous chemical accidents [31], railway emergencies [32], and so on. For instance, Tzeng et al. established a scheduling model with the minimal rescue time, the lowest rescue costs, and the highest satisfaction [29]. They studied the earthquake emergency resource scheduling problem with the fuzzy multi-objective programming method.

Studies concentrating on the emergency resource allocation of metro systems have rarely been done. Sun conducted a study on the distribution of resources for all disaster points. The model's goal was to minimize the delivery time of emergency resources and it was solved with Dijkstra's method [33]. Liu divided the problem of metro emergency resource allocation into two stages: Static and dynamic. The model of each stage had different goals, including having the earliest response time and the least rescue stations [34]. However, these studies paid more attention to the formation and calculation of mathematical models. The features of the metro system and different metro emergency scenarios have been described less frequently and have not been targeted enough.

The use of modeling techniques in emergency resource allocation is increasing. Researchers tend to use models as support to give indications to decision-makers. The reviewed models involve static models and dynamic models according to whether the parameters change over time. With regard to static models, a two-stage stochastic programming model was exhibited in earthquake disasters to allocate first-aid resources [27]. Ni et al. built a model combining site selection, emergency inventory pre-positioning, and emergency resource allocation in a relief network that was characterized by the uncertainty of emergency sites and the road capacity. The application of this model was illustrated by the 2010 Yushu earthquake in Qinghai province [30]. As for dynamic models, dynamic distributed constraint conditions were proposed to account for the dynamic and distributed nature of emergency rescue resources to enhance the distribution of emergency resources [35]. Zheng et al. regarded resource 
allocation as a multi-stage and non-cooperative game process targeted at minimal losses. A dynamic multi-resource allocation model was put forward, and an improved cuckoo search algorithm was designed to work out the problem [32].

Many real-world problems actually involve simultaneously optimizing objectives, such as the minimization of costs, the maximization of satisfaction, the maximization of reliability, and other objectives [36]. In the area of resource allocation research, Suleyman and William argue that emergency resource allocation is essentially a multi-objective optimization problem under various constraints [37]. Many scholars have established models with multiple objectives as well. Generally speaking, in most models, the shortest resource allocation time [31], the minimization of the total allocation costs, or the minimization of penalty costs caused by delayed rescue remain key pursuits [38-40]. For example, Wang et al. introduced a multi-objective problem aimed at having the earliest start time for the whole emergency process and minimal total resource costs for the disaster area [41]. Paul et al. formulated a two-stage stochastic programming model to minimize four kinds of costs in hurricane rescue, including the commercial logistics costs, deprivation costs, suffering costs, and construction costs. The proposed method provided policymakers with a wise emergency response plan [40]. Huang et al. focused on the minimization of three objectives in disaster response operations, which were life-saving utility, delay cost, and fairness. A variational inequality algorithm was implemented to solve the model [42]. These models have some implications for our research, such as the related parameters as well as objective considerations.

\subsection{Scenario Analysis Theories}

The word "scenario" was first put forward by Kahn and Wiener in 1967. They stated that the term "scenario" represents situations which contain factors that promote the development of events. The basic idea of scenario analysis is that the uncertainty of the future is inevitable, but some aspects of future events are predictable [43]. In the field of emergency management, there has been some research using scenario analysis. Chang et al. defined scenarios of disaster occurrence as the possible realization of parameters of unknown problems, and they extracted different flood scenarios by utilizing the network analysis and data processing functions of GIS [44]. Mete and Zabinsky studied earthquake scenarios and included certain disaster information in each earthquake scenario, such as emergency resource demand and emergency response time [39]. Rawls and Turquist took historic data from 15 hurricanes as the basic data for constructing scenarios. They constructed 51 hurricane scenarios, and defined scenarios from three aspects: Post-disaster forecast demand, post-disaster proportion of available storage, and post-disaster road capacity [45].

Scenario analysis has also been applied in metro emergency management. For example, according to the characteristics and actual need of metro emergency fire scenarios, Zhang, et al. divided the analysis into three stages, namely, the start of the dangerous phase, dangerous disposal, and the recovery operation phase. The quick scenario information collection and real-time information report allow rescuers to learn more about fire events in an orderly way [46]. Liu constructed a scenario element model with four elements, including disaster body, disaster victims, disaster breeding environment, and disaster resistant bodies. The emergency resources needed in the emergency rescue process were also deduced from the element model [47]. However, these studies focused on early scenario analysis and did not use the analysis for the follow-up scenario response procedures. A particular scenario requires a particular response.

As can be seen, the construction and analysis method of emergency scenario is a valid means of disaster disposal. In the field of emergency management, this method can be used to obtain a series of elements and events that lead to the system's development from the current situation to the future and to help to find feasible solutions. The number and types of emergency resources required in different disasters are different. Although it is difficult to predict in advance, scenario analysis can be used as a basis for assessing the needs of emergency resources as well as to determine the configuration and allocation of emergency resources. In this way, the originally stochastic rescue demands become 
predictable under given scenarios. Thus, the resources can be allocated pertinently to avoid worse consequences. Moreover, the application of scenario analysis makes it easier for professionals with specialized domain knowledge to discuss the emergency schemes. The application of scenario analysis in metro emergencies will make sense.

\subsection{Review Summary}

After reviewing the related work above, we concluded that metro emergency management is a complex and systematic problem and that metro emergency resource allocation is one of the significant components of it. Although previous work is instructive, there are some gaps. Firstly, previous studies of emergency resource allocation have concentrated on areas other than metro systems; despite that, it is a key component. There are few studies focusing on the emergency resource management of metro systems. Secondly, even though some studies have been conducted on metro emergencies, most of them focused on the improvement of models and algorithms and simplified the characteristics of metro circumstances and the analysis of emergency scenarios. They considered all the situations in general and did not design the resource allocation plan according to the specific scenario of the metro accident. Therefore, these studies might not adequately reflect real emergency situations and were full of uncertainty. Emergency resource allocation models are demand-oriented, while resource demand methods are scenario-oriented. More effort should be made to study metro emergency resource allocation by better combining abstract mathematical model language with practical scenarios to facilitate metro emergency management. To fill the gaps above, we developed a multi-objective model for resource allocation during metro emergencies on the basis of scenario analysis and applied this methodology to Nanjing Metro.

\section{The Application of Scenario Analysis in Metro Emergencies}

The metro emergency scenario is a description of all of the state factors involved in the occurrence and development of metro emergencies. Metro emergency scenario analysis is the foundation of scenario-based emergency resources allocation. In view of the characteristics of metro emergencies, the demand for emergency resources at disaster sites is very urgent and a wide range of resources need to be deployed. However, accidents may happen at any time in real metro systems. The location, time, and intensity of accidents are hard to forecast [48]. In order to integrate the internal and external metro system resources in a targeted way and make optimal decisions within a restricted time period while dealing with uncertainty, it is necessary to build an emergency scenario model in order to achieve rapid information transmission and orderly emergency response procedures.

\subsection{Classification of Metro Emergencies}

Figuring out the classification of metro emergencies and emergency resources is the premise of scenario analysis. According to the causes of accidents, metro emergencies can be divided into the following categories: Natural disasters, production safety, social security, and public health. Natural disasters are caused by unavoidable geological and meteorological disasters, such as earthquakes, floods, etc. The causes of production safety emergencies mainly include the following: Firstly, management and organization, such as the unsafe thoughts and behaviors of metro employees. Secondly, equipment technology, such as aging power supply systems and malfunction of signal system. Various kinds of fire, explosion, derailment, collision, and other major production safety accidents are caused by such faults. Social security emergencies are mainly caused by human factors aimed at disrupting public order, like arson, terrorist attacks, etc. They also encompass unsafe actions of passengers, such as jumping off the platform, congestion, carrying inflammable and explosive items, etc. Public health emergencies are mainly caused by biochemical and radioactive contamination, major epidemics, and so on.

According to statistics of major metro accidents from 2000 to 2019, among the metro accidents in previous years, the rate of metro fire (including explosion) has been the highest, accounting for $22.86 \%$. 
The second was train crashes (including rear-end collision) accident which reached $20.00 \%$. The third is crowded stampedes, making up a proportion of $17.14 \%$ [49].

\subsection{Classification of Corresponding Emergency Resources}

According to the different rescue tasks of emergency resources, they can be divided into three categories, namely, site management and support resources, life rescue resources, engineering rescue and professional disposal resources [50]. Site management and support resources mainly include the resources needed to maintain the emergency site and advance rescue process. Life rescue resources focus on people, mainly including resources related to search, rescue, and medical treatment in emergency response. Engineering rescue and professional disposal resources refer to all kinds of tools and equipment for maintaining electric, communication, and professional equipment in the metro system. According to this classification, a part of the emergency resources needed in the four metro emergency types are teased out in Table 1.

Table 1. The corresponding emergency resources needed in different metro emergencies.

\begin{tabular}{|c|c|c|c|}
\hline $\begin{array}{l}\text { Metro Emergency } \\
\text { Types }\end{array}$ & $\begin{array}{l}\text { Site Management and Support } \\
\text { Resources }\end{array}$ & Life Rescue Resources & $\begin{array}{l}\text { Engineering Rescue and } \\
\text { Professional Disposal } \\
\text { Resources }\end{array}$ \\
\hline Natural disasters & $\begin{array}{l}\text { Meteorological monitoring } \\
\text { equipment, aftershock monitoring } \\
\text { equipment, emergency searchlight, } \\
\text { gunny bag, cordon, intercom, } \\
\text { fluorescent indicator rod. }\end{array}$ & $\begin{array}{l}\text { Ventilator, life detector, stretcher, } \\
\text { guide rope, first-aid kit, safety } \\
\text { helmet, bandage, raincoat, life } \\
\text { jacket, toothless saw, chain saw, } \\
\text { glare flashlight, lifeboat. }\end{array}$ & $\begin{array}{l}\text { Electric equipment inspection } \\
\text { car, emergency pump, } \\
\text { high-power drainage } \\
\text { equipment, emergency tool kit. }\end{array}$ \\
\hline $\begin{array}{l}\text { Production safety } \\
\text { emergencies }\end{array}$ & $\begin{array}{l}\text { Cordon, fume extractor, intercom, } \\
\text { poisonous gas detector, emergency } \\
\text { searchlight, emergency evacuation } \\
\text { sign, bus, infrared detector, fire } \\
\text { engine. }\end{array}$ & $\begin{array}{l}\text { Fireproof suit, fireproof gloves, } \\
\text { emergency medicine, stretcher, } \\
\text { wet towel, gas mask, oxygen } \\
\text { ventilator, oxygen bomb. }\end{array}$ & $\begin{array}{l}\text { Hydraulic lifting equipment, } \\
\text { cable tester, screw support } \\
\text { frame, gear box oil, air } \\
\text { compressor filter core, spare } \\
\text { cable conductor, emergency tool } \\
\text { kit. }\end{array}$ \\
\hline $\begin{array}{l}\text { Social security } \\
\text { emergencies }\end{array}$ & $\begin{array}{l}\text { Emergency searchlight, cordon, } \\
\text { emergency evacuation sign, } \\
\text { intercom, poisonous gas detector, } \\
\text { fume extractor, sprinkler system, } \\
\text { explosive detector. }\end{array}$ & $\begin{array}{l}\text { Protective glasses, oxygen } \\
\text { ventilator, fireproof suit, fireproof } \\
\text { gloves, anti-erode gloves, gas } \\
\text { mask, first-aid kit, first-aid } \\
\text { equipment, safety helmet. }\end{array}$ & Blast pipe, emergency tool kit. \\
\hline $\begin{array}{l}\text { Public health } \\
\text { emergencies }\end{array}$ & $\begin{array}{l}\text { Microbiological detector, } \\
\text { disinfectant, interphone, } \\
\text { loudspeaker. }\end{array}$ & $\begin{array}{c}\text { Vaccine, oxygen ventilator, } \\
\text { medical protective mask, forehead } \\
\text { temperature gun, defibrillation } \\
\text { pacemaker. }\end{array}$ & Epidemic prevention vehicle. \\
\hline
\end{tabular}

\subsection{Scenario Analysis of Metro Emergencies}

The metro emergency scenario element system consists of two levels. Firstly, the main elements covering the states of metro emergency were extracted and determined. Secondly, the detailed scenario elements of metro emergency were extracted. For better information transmission, the representation needed to follow the same logical framework. Any change in the status will cause variation in the scenario elements.

The first level of the emergency scenario system was constructed from seven dimensions, which were event, passenger, time, location, environment, demand, and supply. The extraction of the seven dimensions were determined and classified from two aspects: Practical disposal regulations and existing studies on metro safety management.

From the practical view, as mentioned in the contingency plans for urban rail transit operation emergencies issued by the Chinese State Council, dynamic information of metro operation emergencies should be continuously released. The information should include time, location, cause, accident type, casualties, rescue progress, range, regional traffic conditions, and other information, which are key elements of an emergency scenario in the metro system.

From the literature view, different scholars have different research emphases and put forward different scenario elements. Fan classified scenario elements into emergency, disaster victims, and emergency 
management [51]. Wu divided the elements into disaster body, disaster victims, disaster breeding environment, and disaster resistant bodies [52]. Han et al. organized the scenario system from the aspects of society, environment, technology, public sentiment, resources, organization, and casualties [53]. Considering the complexity of the metro emergencies, the causing-bearing-breeding-fighting chain was applied in the scenario analysis according to the development of an emergency. Causing refers to the event dimension. Bearing covers the passenger dimension and location dimension, which suffer from the accidents. Breeding includes the environment dimension and time dimension, which may have an impact on the implementation of rescue. Fighting refers to the demand dimension and supply dimension, which is the response to the metro emergency. Therefore, the scenario element system of metro emergencies can be built, consisting of the seven dimensions mentioned above. Furthermore, the sources of each scenario element of the second level are summarized in Table 2.

Table 2. The sources of the scenario elements.

\begin{tabular}{|c|c|c|}
\hline \multicolumn{2}{|c|}{ Scenario Elements } & Literature Sources \\
\hline \multirow{4}{*}{ Event } & Emergency type & [54] \\
\hline & Event cause & [54] \\
\hline & Influence range & [55] \\
\hline & Event stage & [55] \\
\hline \multirow{3}{*}{ Passenger } & Passenger flow volume & {$[16,56]$} \\
\hline & Passenger flow density & {$[16,56]$} \\
\hline & Number of stranded people & {$[16,56]$} \\
\hline \multirow{4}{*}{ Time } & The occurrence time & [57] \\
\hline & Current time & [57] \\
\hline & Passenger flow period & [56] \\
\hline & Special date & [57] \\
\hline \multirow{4}{*}{ Location } & Line & [58] \\
\hline & Station & {$[6]$} \\
\hline & Station type & [59] \\
\hline & Specific spot & [58] \\
\hline Environment & Weather & {$[60,61]$} \\
\hline \multirow{3}{*}{ Demand } & Resource demand location & {$[33,34,62]$} \\
\hline & Resource type & {$[33,34,62]$} \\
\hline & Demanded resource quantity & {$[33,34,62]$} \\
\hline \multirow{2}{*}{ Supply } & Resource storage location & {$[52,62]$} \\
\hline & Resource inventory quantity & {$[52,62]$} \\
\hline
\end{tabular}

As for the second level of the scenario element system, the event dimension includes elements such as emergency type, event cause, influence range, and event stage. Among the elements, the influence range element can be further subdivided into the estimated operation interruption time, the number of fatalities, the number of wounded, and property loss. When a practical emergency is described, the attributes of the influence range are often not exact values but are estimated values or even estimated intervals. The stage element can be described as the initial stage, middle stage, and end stage.

The passenger dimension can be divided into the passenger flow volume, passenger flow density, and number of stranded people. As passenger transport is the core task of urban metro operation, and because the distribution of passenger flow shows distinction and complicacy, passenger flow information is very critical [56].

The time dimension includes the occurrence time, current time, passenger flow period, and special date. The passenger flow period element can be split into peak period, secondary peak period, and non-rush period. Special date refers to weekends and holidays [57].

The location dimension can be represented by the line, station, station type, and specific spot. The station type element contains the transfer station, terminal station, and normal station [59]. The specific spots include places such as carriages, platforms, gate machines, ladders, and tunnels. 
The environmental dimension mainly refers to weather information. Weather is a factor which should not be overlooked when encountering severe weather such as sudden rain and snow, typhoon, and flood [63]. The weather information includes current weather and future weather.

The demand dimension can be represented by resource demand location, resource type, and demanded resource quantity.

The supply dimension can be represented by resource storage location and resource inventory quantity.

Thus, a two-level scenario element system of metro emergencies can be built.

\subsection{Logic Framework}

To sum up and to lead to the following sections, the logic framework of the scenario-based resource allocation model for metro emergencies is demonstrated in Figure 1.

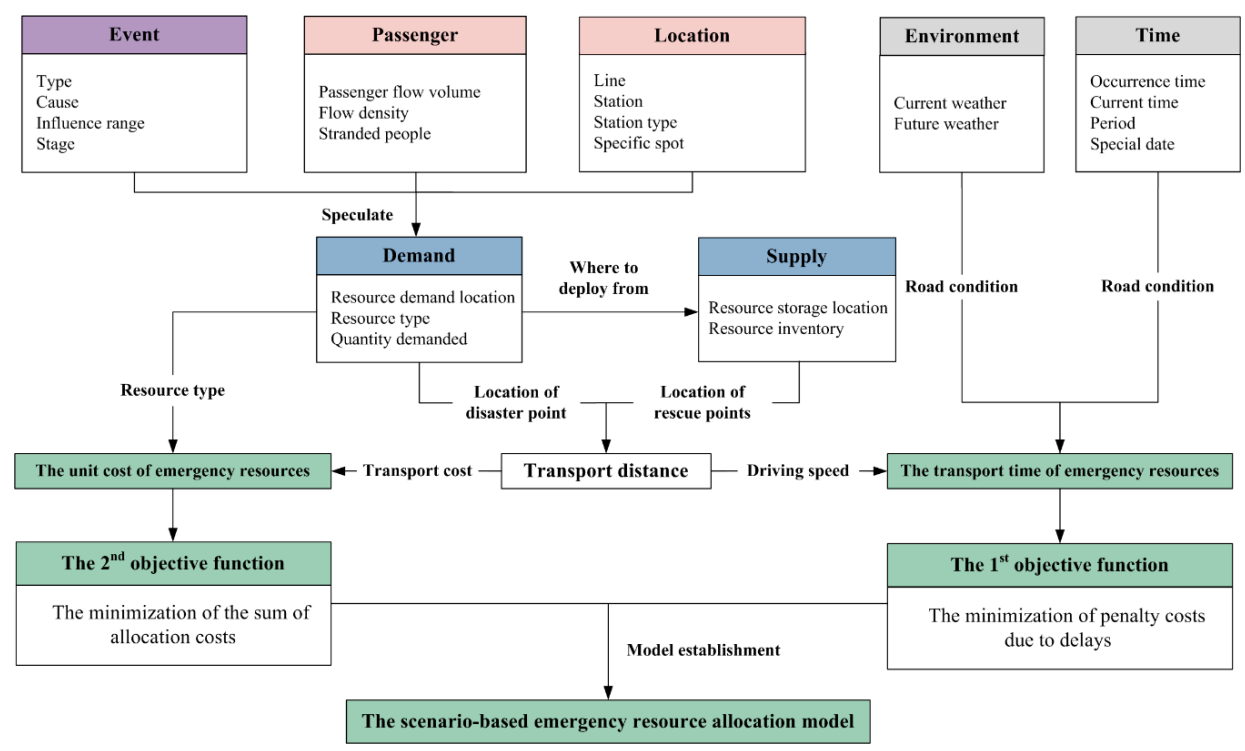

Figure 1. Logic framework of the scenario-based resource allocation model for metro emergencies.

As is shown in Figure 1, the key elements and the relationships between the elements of the metro emergency scenario can be found. The different parts of the causing-bearing-breeding-fighting mode are separated by different colors. Where emergencies occur is generally where resources are needed. The types of resources are based on the event element. The numbers of each demanded resource by the disaster site are based on the event element and the passenger element of the metro emergency scenario. Once the demand has been identified, the resource storage location and resource inventory need to be further pinpointed. The unit cost of each emergency resource allocated from the rescue points consists of two parts: The use cost and transport cost. The use cost depends on emergency resource type and the transport cost depends on transport distance.

Using geographic information, the estimated values of distances from the rescue points to the disaster point can be given. Thus, the estimated transport time of emergency resources can be inferred by combining the distance information with the driving speed of the rescue vehicles. In practical terms, the transportation of emergency resources will be affected by road conditions. Rough weather and traffic jam at rush hours both postpone the allocation. The transport time can be adjusted by corresponding coefficients under these negative conditions. Rough weather may also aggravate metro emergencies.

The methodology of this study is based on the scenario-response mode in which the optimal emergency response decisions are made according to scenario analysis. In the scenario-response mode, emergency resource demands and other necessary information can be derived from scenario analysis 
and then optimization decisions can be made based on the obtained information. The change of scenarios can be realized by changing the element values in the universal scenario system. The decisions also change as the scenarios change. Based on the elements obtained from the scenario analysis, the fourth section describes the establishment of the multi-objective model related to the minimization of penalty costs due to delays and the minimization of the sum of allocation costs, which can output a nearly-optimal resource allocation scheme that satisfies the requirement of the two objectives. The transport time and the unit cost of emergency resources are two dominating modeling parameters. Some scenario elements are directly input as state variables such as the station, resource type, resource inventory, and so on. Other elements not only provide a basis for decision makers to formulate the disposal plan, but also provide a rich historical database for research in the field of metro safety management which allows easy access and seamless collaboration.

\section{Resource Allocation Model for Metro Emergencies}

\subsection{Model Development}

\subsubsection{Explanation of Hypothesis}

(1) Based on scenario analysis, the location of the emergency event, the location of the alternative emergency rescue stations, the event scale, and other necessary information are already known.

(2) The emergency transportation time from each rescue point to the disaster point can be determined after comprehensive consideration of weather, road condition, and distance.

(3) It is assumed that only the road transport method is used, and the constraint of vehicle capacity is not considered.

(4) The loss caused by non-timely rescue in the initial emergency response stage is not considered.

\subsubsection{Modeling}

The descriptions of variables and parameters assumed in the mathematical model are displayed in Table 3.

Table 3. The descriptions of notations.

\begin{tabular}{|c|c|}
\hline Notation & Description \\
\hline E & Disaster point. \\
\hline $\mathrm{w}$ & The number of emergency resource types. \\
\hline$x_{i}^{k}$ & Decision variable which represents the number of type k resources allocated from rescue point $S_{i}$ to disaster point $E$. \\
\hline$p_{i}^{k}$ & The type k emergency resource inventory owned by rescue point $S_{i}$. \\
\hline$d_{k}$ & Type k emergency resource demanded by disaster point E. \\
\hline$t_{i}$ & Emergency resource transport time from rescue point $S_{i}$ to disaster point $E$. \\
\hline $\mathrm{T}$ & $\begin{array}{l}\text { Maximum time spent in delivering resource from an emergency rescue point to a disaster point, as set forth in the } \\
\text { contingency plan of the metro management department. }\end{array}$ \\
\hline$\beta_{i}$ & $\begin{array}{l}\qquad=\left\{\begin{array}{c}0, t_{i}-T \leq 0 \\
1,0<t_{i}-T \leq 5 \\
2,5<t_{i}-T \leq 10 \\
10,10<t_{i}-T \leq 20 \\
100, t_{i}-T>20\end{array}, \text {, [64] }\right. \\
\text { It is the penalty cost coefficient of losses caused by the delay of emergency resources per unit of time and quantity, which } \\
\text { is calculated according to different delay time. In order to facilitate calculation, it is assumed that the coefficients of } \\
\text { various resources are the same in the same time interval. Usually, the coefficient increases sharply when the delay time is } \\
\text { close to the bearing limit of the disaster point. }\end{array}$ \\
\hline
\end{tabular}


Taking an overall view of the issue, the mathematical formulation of the allocation model is expressed in the equations as below:

$$
\begin{gathered}
\min \sum_{k=1}^{w} \sum_{i=1}^{n} \beta_{i} \cdot x_{i}^{k} \cdot\left(t_{i}-T\right) \\
\min \sum_{k=1}^{w} \sum_{i=1}^{n} c_{i}^{k} \cdot x_{i}^{k} \\
\text { s.t. }\left\{\begin{array}{l}
\sum_{i=1}^{n} x_{i}^{k} \geq d_{k}, k=1,2, \cdots w \\
x_{i}^{k} \leq p_{i}^{k}, k=1,2, \cdots w, i=1,2, \cdots n \\
\sum_{i=1}^{n} \lambda_{i} \cdot x_{i}^{k}>0, k=1,2, \cdots w \\
x_{i}^{k} \geq 0, x_{i}^{k} \in N
\end{array}\right.
\end{gathered}
$$

\subsubsection{Model Analysis}

In a metro emergency scenario, the timeliness of rescue service and economic factor were selected as optimization objectives. As for the timeliness objective, the time taken for metro emergency resource allocation is a mandatory rule to some extent. Various countries list the emergency rescue time in their standards, such as the American standard for fixed guide way transit and passenger rail systems. Nanjing Metro released a flowchart of emergency rescue, showing the required time taken by each emergency link, such as for failure notification, arrival of emergency vehicles, and other activities. The efficiency of resource allocation directly determines the emergency capability of the metro station in response to various emergencies, which is of great significance for the smooth implementation of disaster control and emergency activities. Therefore, time was chosen as an important modeling objective.

The economic objective is the other factor that deserves consideration. At present, in the process of urban metro emergency management, large instruments and emergency vehicles are usually set up in fixed bases. Regular emergency resources are stored at some but not all metro stations. In the process of resource allocation, it is also necessary to weigh the relationship between allocation cost and rescue performance. On the premise of meeting disaster relief demand, reasonable planning of rescue cost is conducive to realizing maximum efficiency of resources. Under the current economic and technological constraints, unrestricted allocation will result in a waste of resources. In actual recue activities, the time factor is prior to the economic factor.

(1) Objective Function Analysis

Objective (1) is the minimization of penalty costs due to delays of emergency resources to the disaster site, indicating the timeliness of rescue.

The time for emergency resources to reach the disaster site may exceed the emergency limit time, leading to situations where certain types of emergency resource requirements are not met. Accordingly, there will be losses which should be kept as small as possible. The penalty cost is aimed at measuring the losses caused by the delay of emergency resources. The concept of penalty cost has appeared in previous studies on emergency resource allocation. Sun and Pan mapped the loss costs to the length of delay time and established a mathematical model aiming at the minimum number of rescue points and the minimum loss costs [65]. Yu et al. defined the penalty cost as a linear function of the difference between the demanded quantity and supplied quantity to assess the loss caused by disasters [66]. As can be seen, the penalty cost not only reflects the urgency of emergency rescue, but also reflects the damage to the system. It makes the seemingly immeasurable losses quantitative. 
In this paper, the penalty cost is the product of the penalty cost coefficient $\beta_{i}$, the allocation quantity of each emergency resource $x_{i}{ }^{k}$, and the delayed time $\left(t_{i}-T\right)$, which can be represented by this expression:

$$
\sum_{k=1}^{w} \sum_{i=1}^{n} \beta_{i} \cdot x_{i}^{k} \cdot\left(t_{i}-T\right)
$$

The value of $\beta_{\mathrm{i}}$ was set according to an investigation to several experts implemented by another researcher [64]. The investigation evaluated different levels of the costs of property damage and casualties due to resource delays. There were totally five levels according to the length of the delay time. The value of $\beta_{i}$ varies according to different delay time of the resources. The coefficient increases sharply as the delay time is close to the bearing limit of the disaster point. The value of $\beta_{i}$ requires to be further defined during actual use.

In rescue activities, time is the most dominant factor. Timely assistance signifies that more lives can be saved, and the damage can be reduced [67]. Therefore, decreasing losses from delays in emergency resources should be the most important rescue objective.

Objective (2) shows that in the process of metro emergency rescue, the economic factor is also analyzed. Having minimal allocation costs is regarded as the second goal.

(2) Constraint Function Analysis

In constraint condition (3), article 1 indicates that the total number of type $\mathrm{k}$ resources supplied by the activated rescue point ought to meet the demands of the disaster point; article 2 shows that the amount of type k emergency resource allocated from $S_{i}$ is less than its inventory; article 3 indicates that at least a portion of each kind of resource should reach the disaster site within the emergency time limit; and the fourth factor is the non-negative constraint and integer constraint on decision variables.

(3) Model Transformation

The proposed model is a double objective optimization and the aim of the two goals is to achieve their minimum values. In order to construct the fitness function in the algorithm, the multi-objective optimization problem is transformed into a single-objective one. $F_{1}(x)$ is the function used to represent objective (1), and $F_{2}(x)$ is used to represent objective (2). $\eta_{1}$ and $\eta_{2}$ are weight coefficients. Therefore, the transformed single-objective function $F(x)$ is:

$$
F(x)=\eta_{1} F_{1}(x)+\eta_{2} F_{2}(x)=\eta_{1} \sum_{k=1}^{w} \sum_{i=1}^{n} \beta_{i} \cdot x_{i}^{k} \cdot\left(t_{i}-T\right)+\eta_{2} \sum_{k=1}^{w} \sum_{i=1}^{n} c_{i}^{k} \cdot x_{i}^{k}
$$

There are many methods that can be used to determine the values of $\eta_{1}$ and $\eta_{2}$. Subjective weighting methods include the analytic hierarchy process (AHP) method, and the Delphi method, and objective weighting methods chiefly include the dispersion method, principal component analysis method, and entropy method [68].

\subsection{Model Solving Algorithm}

There are several ways to seek the optimal solution such as the ant colony algorithm, Dijkstra's method, cuckoo algorithm, and genetic algorithm. Particle swarm optimization (PSO) is a biologically inspired method [69], which performs well without the influence of population size and converges very quickly to the optimal solution [70]. Based on its advantages over other algorithms and its suitability to this problem, the PSO algorithm was chosen to solve the proposed model.

The parameters of PSO algorithm include the population size N, the dimensions of the search space $D$, the self-cognition coefficient $c_{1}$, the group-cognition coefficient $c_{2}$, the maximum number of iterations $T_{\max }$, the maximum position coordinate value $x_{\max }$, the maximum velocity $V_{\max }$, the upper bound of inertia weight $\delta_{\max }$, and the lower bound of inertia weight $\delta_{\min }$. 
The PSO algorithm adopts the velocity-position search model, which is based on particle search in the solution space. In each iteration step, the algorithm is carried out by adjusting the moving distance rate of each particle in each dimension of the solution space. Therefore, each particle has two characteristics, which are position and velocity. $X_{i d}(t)$ is the position vector. The function value of the position coordinate is used as the fitness value of the particle. The maximum position coordinate value $\mathrm{x}_{\max }$ represents the maximum distance over which a particle can search. $\mathrm{V}_{\mathrm{id}}(\mathrm{t})$ is the velocity vector, representing the velocity of the ith particle in the $d$ th dimension of the solution space. The velocity determines the displacement of each iteration of each particle in the search space, namely step size [71]. The particle rate updating formula contains random variables, which may produce a large velocity value in the iteration process. Consequently, the particles may run out of the solution space and generate damped vibration. In order to avoid this phenomenon, the upper and lower limits of velocity can be defined [72]. $V_{\max }$ is equivalent to the maximum value of each forward step. The settings of $\mathrm{V}_{\max }$ depend mainly on the optimization precision. If $\mathrm{V}_{\max }$ is too large, the particle may run unsteadily. The search process will be too fast to find the optimal solution. On the other hand, if $V_{\max }$ is too small, the motion of the particle will be limited, and the optimal solution might not be obtained. Previous research suggested that it should ideally be less than $20 \%$ of the maximum search space [73].

The computational process is illustrated in Figure 2. In every iteration $t$, by searching for the individual extreme value $p_{i}$ and the global extreme value $p_{g}$ of the fitness values, the speed and position of each particle are constantly updated and the fitness values are compared until the optimal solution is finally found. The update formulas are shown below:

$$
\begin{gathered}
V_{i d}(\mathrm{t})=\delta(t) \cdot V_{i d}(t)+c_{1} \cdot \text { rand } \cdot\left(p_{i}-X_{i d}(t)\right)+c_{2} \cdot \text { rand } \cdot\left(p_{g}-X_{i d}(t)\right) \\
X_{i d}(\mathrm{t})=X_{i d}(t)+V_{i d}(t)
\end{gathered}
$$

Rand refers to a random number between $[0,1] . \delta(t)$ represents inertia weight. The PSO algorithm tends to fall into local optimality. So, to balance the global search capability and partial improvement capability of the PSO algorithm, the nonlinear dynamic inertia weight introduced in previous studies was adopted [74,75]. As can be seen from formula (7), the inertia weight $\delta(t)$ changes automatically with the change of iteration.

$$
\delta(t)=\left\{\begin{array}{l}
\delta_{\max }-\left(\delta_{\max }-\delta_{\min }\right)\left(\frac{t}{0.8 T_{\max }}\right)^{0.2}, 1 \leq t \leq 0.8 T_{\max } \\
\delta_{\min }, 0.8 T_{\max } \leq t \leq T_{\max }
\end{array}\right.
$$

The model proposed in Section 4.1.2 is a linear integer programming problem with constraints, and its algorithm elements are as follows: There are $\mathrm{n}$ emergency rescue stations, one disaster point, and $\mathrm{w}$ kinds of emergency resources, so the dimensions of the search space are $\mathrm{n} \times \mathrm{k}$. When designing the algorithm of this model, $X=(x[i, 1], x[i, 2], \ldots, x[i, D])^{\mathrm{T}}$ and $V=(v[i, 1], v[i, 2], \ldots, v[i, D])^{\mathrm{T}}$ can be used to represent the position and velocity of the ith particle. $X$, which represents the number of the emergency resources allocated, is the solution to this problem. The fitness function is,

$$
F(x)=\left(\eta_{1} F_{1}(x)+\eta_{2} F_{2}(x)\right)
$$

which is determined by the optimization objective. The optimal solution of the fitness function when the algorithm terminates is the optimal solution of the model. 


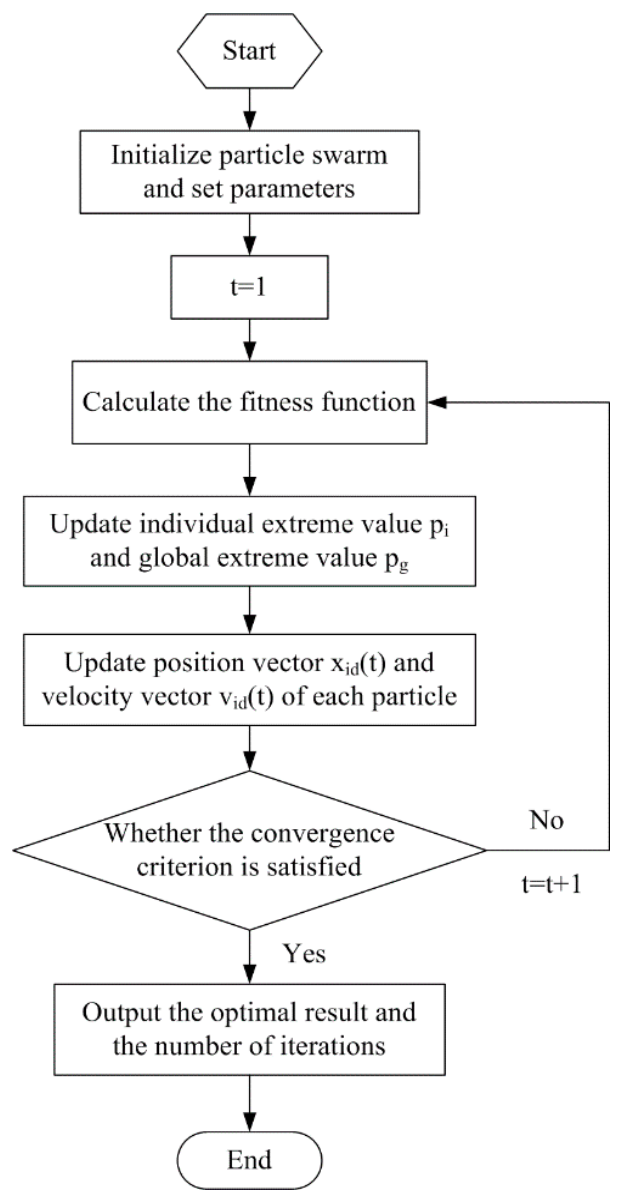

Figure 2. The flowchart of particle swarm optimization (PSO) algorithm.

\section{Case Study}

\subsection{Scenario Description}

As of 2019, Nanjing Metro had opened 10 lines and 174 stations and had a total length of $378 \mathrm{~km}$, ranking the fourth largest in China and the fifth largest in the world. Based on the scale and nature of the Nanjing rail transit network, this section applies the proposed model to the Nanjing metro network and determines the allocation of emergency resources under a hypothetical emergency scenario. A typical fire scenario caused by electrical equipment failure is considered to verify the proposed methodology.

According to the contingency plan of Nanjing Metro operating company, the emergency response time should be no more than $20 \mathrm{~min}$. According to the road traffic situation in Nanjing, the average driving speed of an emergency rescue vehicle is approximately $40 \mathrm{~km} / \mathrm{h}$ under normal circumstances, and this is the pre-requisite for this case.

Based upon the line structure of the metro system, the stations within the system were mapped as nodes of the network. The intervals between two stations were abstracted as the edges between nodes. In emergencies of certain scale, a single emergency rescue station is usually unable to meet the needs of a single disaster point. Therefore, the combining optimization of multiple emergency rescue stations was considered to ensure overall coordination of rescue resources allocation. Five emergency rescue stations were taken as alternatives for practical application: $S_{1}, S_{2}, S_{3}, S_{4}$, and $S_{5}$, respectively. The disaster point was assumed to be Andemen station. The specific distribution is illustrated in Figure 3. 


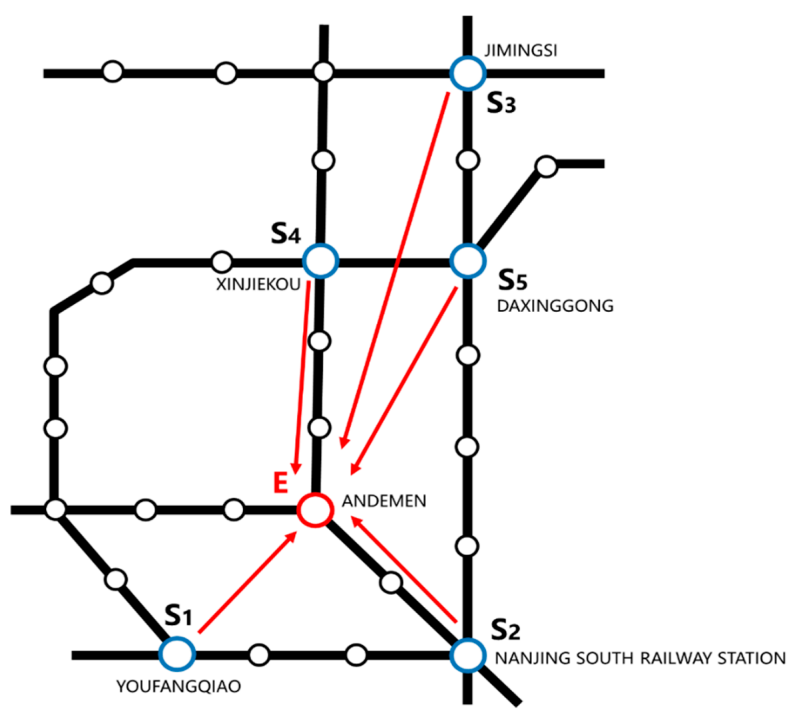

Figure 3. The diagram of rescue points and disaster point.

Figure 4 illustrates the scenario element system of the fire accident assumed for this case study, from which we can intuitively see the specific scenario information of all seven dimensions of the fire accident. Emergency resources can be allocated according to the extracted scenario knowledge displayed. Some of the data are predicted values, which were used for computational reference. In order to simplify the calculation, a unified quantification unit was used. As for the demand dimension, we assumed that three kinds of emergency resources needed to be deployed after this emergency, namely, the gas mask $\mathrm{w}_{1}$, emergency searchlight $\mathrm{w}_{2}$, and fume extractor $\mathrm{w}_{3}$. The number of gas masks required by the disaster site is presented as $d_{1}$. We assumed that sufficient emergency supplies had been pre-positioned in the corresponding rescue points at an earlier stage. The number of gas masks, emergency searchlights and fume extractors stored in rescue point $S_{1}$ are denoted as $p_{1}{ }^{1}$, $\mathrm{p}_{1}{ }^{2}$, and $\mathrm{p}_{1}{ }^{3}$, respectively. The rest can also be expressed in this way. Moreover, the estimated value of transport time from each rescue point to the disaster point and the unit costs of all kinds of emergency resources stored at each rescue point are also provided in Figure 4.

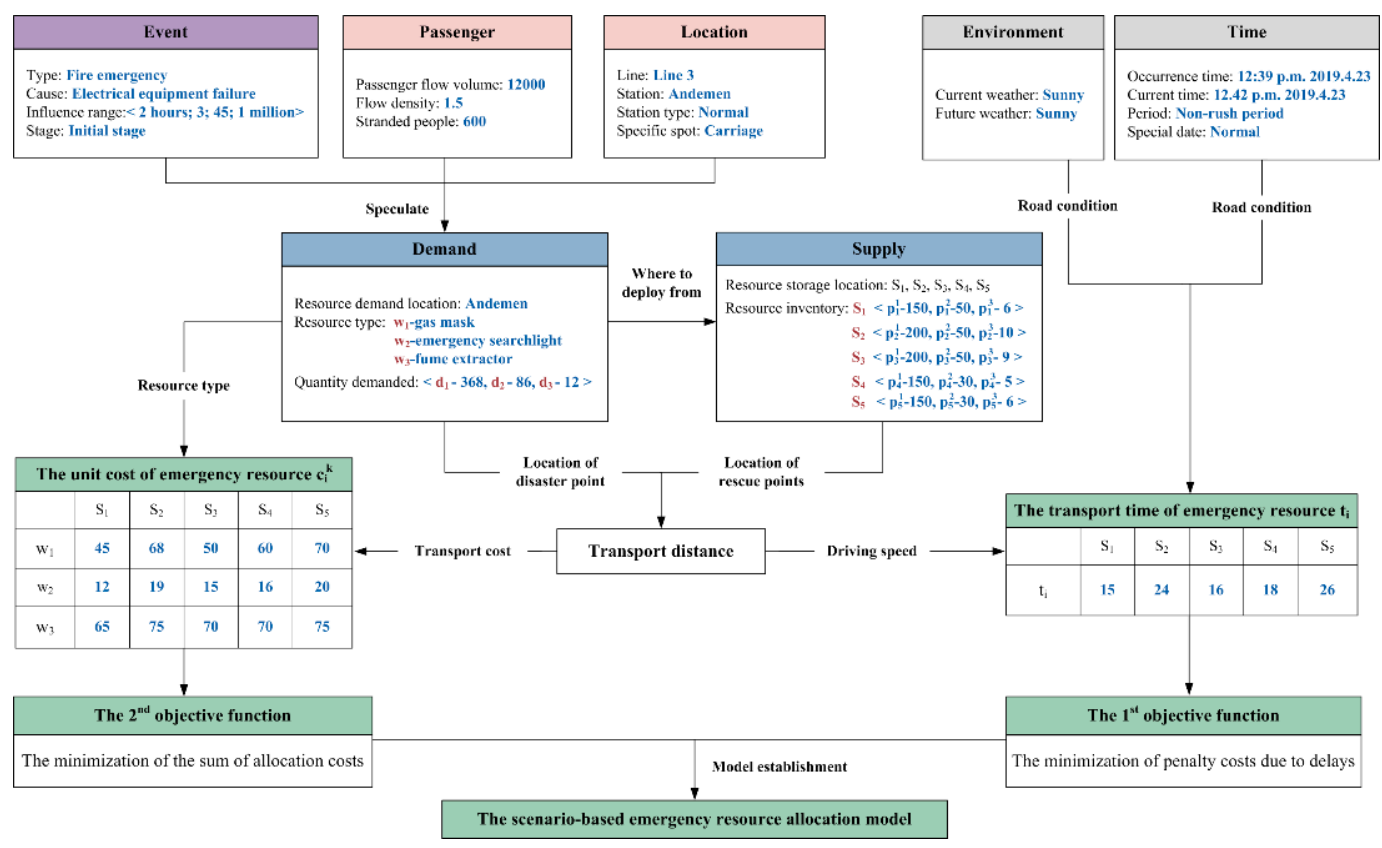

Figure 4. The scenario element system of the fire accident. 


\subsection{Computational Results}

The computer used to solve the problem was installed with the Microsoft Windows10 system. MATLAB was used for programming. The programming consisted of the initialization of parameters, calculation of the fitness value, updating of particles' speeds and positions, termination, and other main modules. In view of the superior influence of the time factor in rescue work, the weight coefficient $\eta_{1}$ of the first target was set as 0.70 , and the weight coefficient $\eta_{2}$ of the second target was set as 0.30 . To ensure global optimal search and convergence of the PSO algorithm, concrete setting values of the parameters are shown in Table 4. The maximum position coordinate value $x_{\max }$ was set to 250 . According to the description in Section 4.2, the maximum velocity $\mathrm{V}_{\max }$ was set to 10 accordingly. The upper and lower boundary values of the inertia coefficient were set to 0.9 and 0.4 , respectively. The self-cognition coefficient $c_{1}$ and the group-cognition coefficient $c_{2}$ were both set to 1.424 [76]. After running the program, the optimal solution was obtained.

Table 4. Parameters setting of PSO algorithm.

\begin{tabular}{cc}
\hline Parameters & Value \\
\hline Initial population size N & 200 \\
Search space dimensions D & 15 \\
Maximum number of iterations $\mathrm{T}_{\max }$ & 1000 \\
Maximum position coordinate value $\mathrm{x}_{\max }$ & 250 \\
Maximum velocity $\mathrm{V}_{\max }$ & 10 \\
Upper bound of inertia weight $\delta_{\max }$ & 0.9 \\
Lower bound of inertia weight $\delta_{\min }$ & 0.4 \\
Self-cognition coefficient $\mathrm{c}_{1}$ & 1.424 \\
Group-cognition coefficient $\mathrm{c}_{2}$ & 1.424 \\
\hline
\end{tabular}

The results represent the numbers of three kinds of emergency resources provided by the five rescue points to the disaster site $\mathrm{E}$. The final optimal allocation scheme is presented in Table 5.

Table 5. The computational results from PSO algorithm.

\begin{tabular}{cccccc}
\hline Rescue Point & $\boldsymbol{S}_{\boldsymbol{1}}$ & $\boldsymbol{S}_{\mathbf{2}}$ & $\mathbf{S}_{\mathbf{3}}$ & $\boldsymbol{S}_{\boldsymbol{4}}$ & $\boldsymbol{S}_{\mathbf{5}}$ \\
\hline $\mathrm{w}_{1}$ & 100 & 0 & 200 & 68 & 0 \\
$\mathrm{w}_{2}$ & 25 & 0 & 50 & 11 & 0 \\
$\mathrm{w}_{3}$ & 3 & 0 & 9 & 0 & 0 \\
\hline
\end{tabular}

As visualized in Figure 5, the number of emergency rescue stations launched is $3: S_{1}, S_{3}$, and $S_{4}$. One hundred gas masks, 25 search lights, and three fume extractors are allocated from the rescue point $\mathrm{S}_{1}$ to the disaster point $\mathrm{E}$. Two hundred gas masks, 50 search lights, and nine fume extractors are allocated from the rescue point $S_{3}$ to the disaster point E. Sixty-eight gas masks and 11 search lights are allocated from the rescue point $S_{4}$ to the disaster point $E$. Under this allocation scheme, not only the demands of all the three types of emergency resources are met, but all the resources are also transported to the disaster point $\mathrm{E}$ as soon as possible. The penalty cost due to delays is 0 and the sum of the allocation costs is also the lowest. The optimal value of the fitness function $F(x)$ is 6269 . 


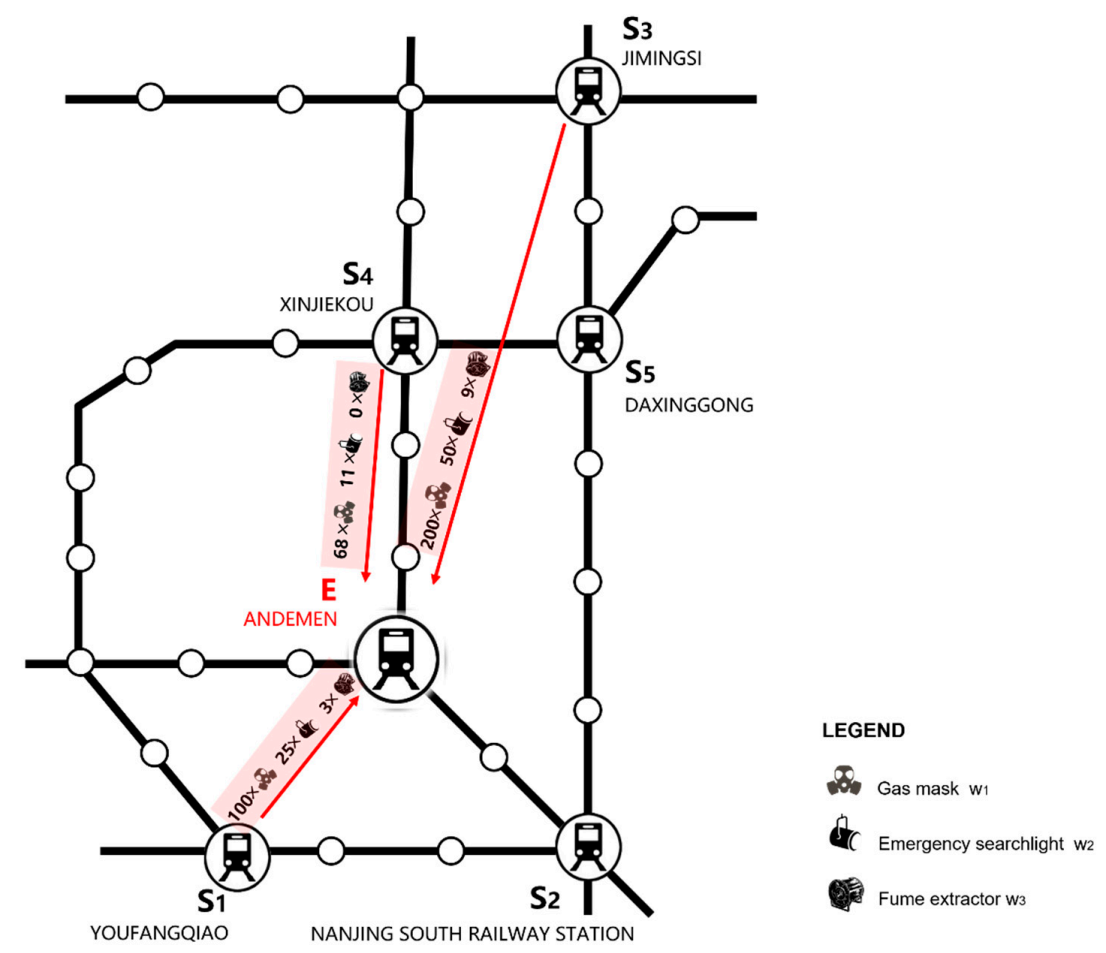

Figure 5. The diagram of the optimal emergency resource allocation scheme.

\subsection{Sensitivity Analysis}

The expression of the sensitivity function is,

$$
F(x)=\eta_{1} \sum_{k=1}^{w} \sum_{i=1}^{n} \beta_{i} \cdot x_{i}^{k} \cdot\left(t_{i}-T\right)+\eta_{2} \sum_{k=1}^{w} \sum_{i=1}^{n} c_{i}^{k} \cdot x_{i}^{k}
$$

which is the same as the fitness function as well as the previous transformed single-objective function. $\mathrm{N}$ is the number of rescue points, and $\mathrm{w}$ is the number of emergency resource types. The descriptions of other parameters can be found in Section 4.1.2. The value of $F(x)$ may vary with the different values of parameters. Therefore, the purpose of the sensitivity analysis is to evaluate the effects of certain parameters on the rescue performance. It can be inferred from the expression of $F(x)$ that the smaller the value, the better the rescue performance, indicating less time and lower costs. In this section, sensitivity analysis was conducted by changing the number of rescue points and the number of resource types while other factors did not change as the number changed. The results of sensitivity analysis are illustrated in Figure 6.

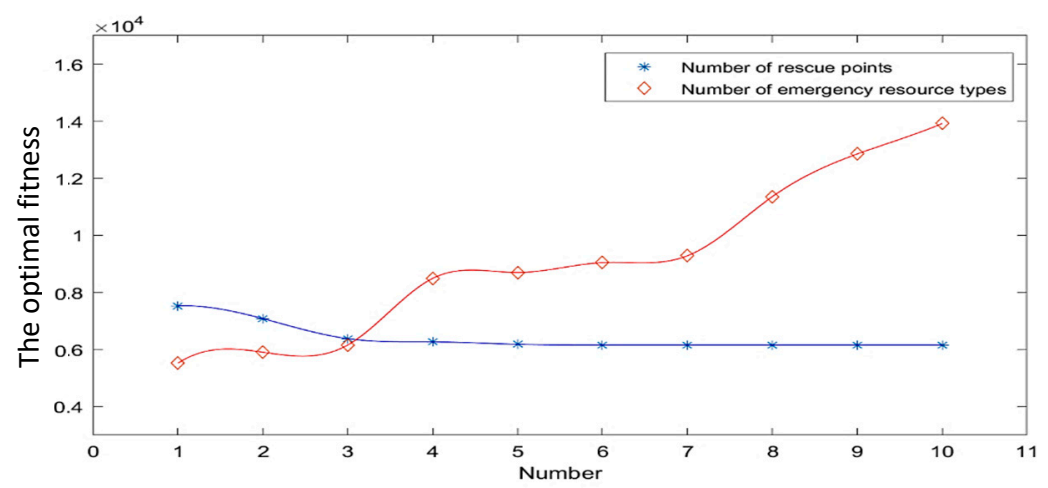

Figure 6. The curves of sensitivity analysis. 
As can be seen from the graph, there is a steady decrease in the optimal fitness value while the quantity of rescue points grows from one to five, indicating that properly adding the quantity of rescue points can improve the rescue performance. However, as the number continues to rise from six, the fitness value remains the same. It can be inferred that having too many rescue stations is not only ineffective for improving rescue performance but also decreases the stability of rescue stations, making it troublesome when there is a disaster elsewhere. Therefore, it is vital to select a reasonable number of emergency rescue points. The graph shows that the best number of rescue points for the scenario above is six.

The other curve shows a stable upward trend, showing that increasing the types of resources has a negative effect on both the rescue time and rescue cost. When the number of emergency resource types increases from one to three and from four to seven, the rise of fitness value is slight. There is a relatively sharp increase when the number rises from seven to ten. The results show that if it is necessary to allocate many kinds of resources, the urgency of the resources could be ranked. Decision makers can prioritize the allocation of more urgent resources. In terms of sensitivity, it can be seen from the slope that the sensitivity of the number of emergency resource types is superior to that of the number of rescue points.

\section{Discussion}

There are few existing studies focused on the emergency resource allocation of the metro system. Under the background of frequent metro emergencies, these findings are significant for decision makers to identify the influencing elements and to enhance the efficiency of emergency rescue. Previous research has established different mathematical models. However, these studies ignore that the emergency resource allocation may be affected by accident types, passenger volume, and other factors of the metro system, which is full of uncertainty. This study introduces the concept of the scenario-response mode. The use of scenario analysis is advantageous compared to previous studies, which is not only targeted at the metro system but also provides the basis for the allocation decision. The emergency type corresponds to the resource types. The numbers of each demanded resource are based on the event element and the passenger element. The location determines the transport distance. The subsequent model establishment and decisions are based on the scenario system. This study suggests that the scenario-response mode is a valid means of disaster disposal.

Furthermore, the case study only considered a fire scenario in the Nanjing Metro. It should be pointed out that the model proposed in Section 4 holds true for most emergency scenarios of the metro system such as derailment, collision, and stampede. When other types of emergency take place, the corresponding emergency data and state in the scenario system need to be changed as the input of the model. However, the model assumes that there is only one disaster point and all the resources need to be allocated to the same station. The increase of disaster points will lead to the change of the expressions of the model as well as the increase of dimension of the search place. Therefore, the model does not apply to accidents with multi disaster points such as flood and earthquake. Given that the scenario element system is standardized, and metro emergencies are common concerns for all countries, the proposed system and model would be suitable for the emergency resource allocation in all metro stations.

\section{Conclusions}

In view of the ever-increasing necessity on metro safety, emergency resource allocation has become one of the important issues in metro emergency management. Due to the sudden and complex nature of metro emergencies, the scenario-response mode was applied in the allocation decision in this paper. This mode included a scenario analysis of metro emergencies and an optimization model for emergency resource allocation on the basis of the scenario analysis in response to potential metro accidents. By taking the Nanjing metro network as an example, a fire accident scenario was considered, and the 
feasibility and validity of the model were demonstrated. The sensitivity of the fitness function was analyzed to provide a deeper understanding. The following conclusions are drawn from this study:

(1) A two-level scenario element system of metro emergencies was established. The first level consists of seven dimensions extracted from practical cases and previous studies, which are event, passenger, time, location, environment, demand, and supply. The second level consists of more detailed scenario elements of each dimension. By considering the different emergency types and obeying the causing-bearing-breeding-fighting chain according to the development of an accident, the proposed scenario system is characterized by the metro and can reflect the relationships between each element.

(2) The scenario-response mode is conducive to improving the efficiency and overall level of emergency decision-making in the metro system. It is of great significance to determine a rational emergency resource allocation scheme based on emergency scenarios. The construction and analysis of emergency scenarios help to sort out the elements immediately and accurately after the accidents, which provide the references and state variables for the formulation of response plans. Besides, the use of the PSO algorithm enables fast and automatic calculation of best solutions under urgent scenarios.

(3) Optimization ideas and tools for the allocation of emergency resources after metro emergencies were provided for decision makers. The proposed method can be set as the modules of the emergency decision-making platform in the metro system. The emergency scenarios serve as the input end and the emergency resource allocation schemes serve as the output end. Through algorithm calculation, the response scheme can be quickly determined. Furthermore, the disaster monitoring and reporting system can be applied in the platform for real-time warning. Remote sensing and geographic information system (GIS) can be used to identify and extract scenario objects and elements. Big data and data base can be used to calculate resource demand. The weather prediction system can also be inserted to obtain current and future weather information. Thus, the automatic emergency allocation is realized.

Meanwhile, there are some limitations of this research. Firstly, there is a deficiency of comprehensive and real data of metro emergencies. Future research may collect more data from practical emergencies. Secondly, the model established in this paper is generally effective for most cases of the four types of accidents, but it is mainly aimed at single point accidents which have a higher occurrence rate, leading to limited generality of the model. Determining how to reasonably distribute emergency resources in multi-point metro accidents is a problem that needs further study.

Author Contributions: Funding acquisition, Y.L.; methodology, Y.L.; writing—original draft, Y.L.; software, S.S.; data curation, S.S. All authors have read and agreed to the published version of the manuscript.

Funding: This research was funded by the National Social Science Foundation of China (Grant No.19BGL238), the Natural Science Foundation of Jiangsu Province, China (Grant No. BK20181276), and the Social Science Foundation of Jiangsu Province, China (Grant No. 17GLB002).

Acknowledgments: Gratitude is expressed to those who offered suggestions to this paper. Sincere gratitude and respect were expressed to all reviewers.

Conflicts of Interest: The authors declare no conflict of interest.

\section{References}

1. Deng, Y.; Song, L.; Zhou, J.; Wang, J. Evaluation and reduction of vulnerability of subway equipment: An integrated framework. Saf. Sci. 2018, 103, 172-182. [CrossRef]

2. An Analysis Report on the Development Prospect and Investment Strategy Planning of Chinese Metro Industry. Available online: https://bg.qianzhan.com/report/detail/459/190410-1b0fb515.html (accessed on 24 January 2020).

3. Ding, X.; Yang, X.; Hu, H.; Liu, Z. The safety management of urban rail transit based on operation fault log. Saf. Sci. 2017, 94, 10-16. [CrossRef]

4. Minciardi, R.; Sacile, R.; Trasforini, E. Resource Allocation in Integrated Preoperational and Operational Management of Natural Hazards. Risk Anal. 2009, 29, 62-75. [CrossRef] 
5. The Contingency Plan for Urban Rail Transit Operation Emergencies. Available online: http://www.gov.cn/ zhengce/content/2015-05/14/content_9751.htm (accessed on 14 May 2015).

6. Li, Q.; Deng, Y.; Liu, C.; Zeng, Q.; Lu, Y. Modeling and analysis of subway fire emergency response: An empirical study. Saf. Sci. 2016, 84, 171-180. [CrossRef]

7. Mendonca, D.; Beroggi, G.E.; Wallace, W.A. Decision support for improvisation during emergency response operations. Int. J. Emerg. Manag. 2001, 1, 30. [CrossRef]

8. Rennemo, S.J.; Rø, K.F.; Hvattum, L.M.; Tirado, G. A three-stage stochastic facility routing model for disaster response planning. Transp. Res. Part E Logist. Transp. Rev. 2014, 62, 116-135. [CrossRef]

9. Caunhye, A.M.; Nie, X.; Pokharel, S. Optimization models in emergency logistics: A literature review. Socio-Econ. Plan. Sci. 2012, 46, 4-13. [CrossRef]

10. Beijing Subway Fire Emergency Response Drill. Available online: https://m.sohu.com/a/122353876_420076/ ?pvid=000115_3w_a (accessed on 23 December 2016).

11. Yan, W.-Y.; Wang, J.-H.; Jiang, J.-C. Subway Fire Cause Analysis Model Based on System Dynamics: A Preliminary Model Framework. Procedia Eng. 2016, 135, 431-438. [CrossRef]

12. Hui, Z.; Yi, L. Key problems on fundamental science and technology integration in "scenario-response" based national emergency response platform system. Syst. Eng. theory Pract. 2012, 32, 947-953.

13. Qilin, S. Study on scenario evolvement and alternative generation of "scenario-response" decision-making in unconventional emergencies. J. Univ. Sci. Technol. China. 2012, 11.

14. Liu, L.; Xu, H.; Li, S.M. A review of the situation and scenario-response theory in emergency management of unconventional emergencies. J. Univ. Electron. Sci. Technol. China 2013, 6, 20-26. [CrossRef]

15. Liu, H.; Chen, H.; Hong, R.; Liu, H.; You, W. Mapping knowledge structure and research trends of emergency evacuation studies. Saf. Sci. 2020, 121, 348-361. [CrossRef]

16. Hong, L.; Gao, J.; Zhu, W. Self-evacuation modelling and simulation of passengers in metro stations. Saf. Sci. 2018, 110, 127-133. [CrossRef]

17. Tsukahara, M.; Koshiba, Y.; Ohtani, H. Effectiveness of downward evacuation in a large-scale subway fire using Fire Dynamics Simulator. Tunn. Undergr. Space Technol. 2011, 26, 573-581. [CrossRef]

18. Hong, L.; Gao, J.; Zhu, W. Simulating emergency evacuation at metro stations: An approach based on thorough psychological analysis. Transp. Lett. 2016, 8, 113-120. [CrossRef]

19. Jiang, C.; Yuan, F.; Chow, W.K. Effect of varying two key parameters in simulating evacuation for subway stations in China. Saf. Sci. 2010, 48, 445-451. [CrossRef]

20. Wang, C.; Song, Y. Fire Evacuation in Metro Stations: Modeling Research on the Effects of Two Key Parameters. Sustainability 2020, 12, 684. [CrossRef]

21. Zhao, M.; Liu, X. Development of decision support tool for optimizing urban emergency rescue facility locations to improve humanitarian logistics management. Saf. Sci. 2018, 102, 110-117. [CrossRef]

22. Deng, Y.L.; Li, Q.M.; Lu, Y.; Song, L.L. Analysis of Site Selection for Metro Emergency Stations in Network Operation. Adv. Transp. Stud. 2013, 32.

23. Zhu, J.M. Methods of multi-objective decision-making for emergency facility location problem under failure scenario. Syst. Eng. Theor. Pract. 2015, 35, 720-727.

24. Zhao, J.; Zhong, S.; Wu, Y.; Yan, X.; Tang, J. Metformin use and survival of lung cancer patients: Meta-analysis findings. Indian J. Cancer 2017, 54, 63. [CrossRef]

25. Feng, J.-R.; Gai, W.-M.; Li, J.-Y. Multi-objective optimization of rescue station selection for emergency logistics management. Saf. Sci. 2019, 120, 276-282. [CrossRef]

26. Kolesár, P.; Walker, W.E. An Algorithm for the Dynamic Relocation of Fire Companies. Oper. Res. 1974, 22, 249-274. [CrossRef]

27. Barbarosoğlu, G.; Arda, Y.; Barbaroso, Y.A.G. A two-stage stochastic programming framework for transportation planning in disaster response. J. Oper. Res. Soc. 2004, 55, 43-53. [CrossRef]

28. Horner, M.W.; Downs, J.A. Optimizing hurricane disaster relief goods distribution: Model development and application with respect to planning strategies. Disasters 2010, 34, 821-844. [CrossRef] [PubMed]

29. Tzeng, G.-H.; Cheng, H.-J.; Huang, T.D. Multi-objective optimal planning for designing relief delivery systems. Transp. Res. Part E Logist. Transp. Rev. 2007, 43, 673-686. [CrossRef]

30. Ni, W.; Shu, J.; Song, M. Location and Emergency Inventory Pre-Positioning for Disaster Response Operations: Min-Max Robust Model and a Case Study of Yushu Earthquake. Prod. Oper. Manag. 2017, 27, 160-183. [CrossRef] 
31. Yin, H. Study on the Optimal Dispatching of Emergency Resources in Dangerous Goods Accidents Under Uncertain Conditions. Master's Thesis, South China University of technology, Guangdong, China, 2013.

32. Zheng, Y.; Mu, R.; Lin, J.; Cheng, L. Research of dynamic multi-stage scheduling decision model and algorithm for railway emergency resources. Comput. Eng. Appl. 2015, 51, 213-219.

33. Sun, C.H. Study on the Configuration Optimization Method of Subway Emergency Resources Based on Network. Master's Thesis, Beijing Jiaotong University, Beijing, China, 2010.

34. Liu, X. Research on the Allocation of Relief Supplies for Subway Emergencies. Master's Thesis, Lanzhou Jiaotong University, Lanzhou, China, 2015.

35. Modi, J.; Jung, H.; Tambe, M.; Shen, W.-M.; Kulkarni, S. Dynamic Distributed Resource Allocation: A Distributed Constraint Satisfaction Approach. Comput. Vis. 2002, 2333, 264-276. [CrossRef]

36. Konak, A.; Coit, D.W.; Smith, A.E. Multi-objective optimization using genetic algorithms: A tutorial. Reliab. Eng. Syst. Saf. 2006, 91, 992-1007. [CrossRef]

37. Suleyman, A.W. The emerging area of emergency management and engineering. IEEE Trans. Eng. Manag. 1998, 45, 103-105.

38. Pan, Y.; Yu, J.; Da, Q.L. Emergency resources scheduling on continuous consumption system based on particle swarm optimization. J. Syst. Eng. 2007, 22, 556-560. [CrossRef]

39. Mete, H.O.; Zabinsky, Z.B. Stochastic optimization of medical supply location and distribution in disaster management. Int. J. Prod. Econ. 2010, 126, 76-84. [CrossRef]

40. Paul, J.A.; Zhang, M. Supply location and transportation planning for hurricanes: A two-stage stochastic programming framework. Eur. J. Oper. Res. 2019, 274, 108-125. [CrossRef]

41. Wang, S.S.; Wang, Y. Emergency Resources Allocation among Multiple Disaster Places under Fair Priority Principle. Oper. Res. Manag. Sci. 2008, 3, 16-21.

42. Huang, K.; Jiang, Y.; Yuan, Y.; Zhao, L. Modeling multiple humanitarian objectives in emergency response to large-scale disasters. Transp. Res. Part E Logist. Transp. Rev. 2015, 75, 1-17. [CrossRef]

43. Lou, W. The theory of scenario analysis. Future Dev. 2012, 9, 17-26.

44. Chang, M.-S.; Tseng, Y.-L.; Chen, J.-W. A scenario planning approach for the flood emergency logistics preparation problem under uncertainty. Transp. Res. Part E Logist. Transp. Rev. 2007, 43, 737-754. [CrossRef]

45. Rawls, C.G.; Turnquist, M.A. Pre-positioning of emergency supplies for disaster response. Transp. Res. Part B Methodol. 2010, 44, 521-534. [CrossRef]

46. Zhang, J.L.; Li, R.; Liu, X.T. Analysis of emergency treatment process based on fire scenario of subway tunnel. Trans. Enterp. Manag. 2016, 31, 65-67. [CrossRef]

47. Liu, T.M. Studies on scenes construction of emergency planning. J. Saf. Sci Technol. 2012, 8, 5-12.

48. Lu, Y.; Li, Q.; Xiao, W. Case-based reasoning for automated safety risk analysis on subway operation: Case representation and retrieval. Saf. Sci. 2013, 57, 75-81. [CrossRef]

49. Wang, S.L. Study on Pedestrian Emergency Evacuation Behavior and Simulation of Subway Station. Master's Thesis, Zhengzhou University, Henan, China, 2019.

50. National Development and Reform Commission. The Catalogue of Key Emergency Support Resources; NDRC: Beijing, China, 2015.

51. Fan, W.C.; Liu, Y.; Wen., W.G. Triangular Framework and "4+1" Methodology for Public Security Science and Technology. Sci. Technol. Rev. 2009, 6, 3.

52. Wu, Q.; Tan, W.; Gai, W.W. Study on scenario analysis of civil aviation emergency based on dynamic Bayesian network. J. Saf. Sci. Technol. 2016, 3, 169-174.

53. Han, C.F.; Wang, X.G.; Kong, J.J. Dynamic Mechanism of Unconventional Emergency Decision-making System. Soft. Sci. 2009, 8, 50-53.

54. Paragios, N.; Ramesh, V. A MRF-based approach for real-time subway monitoring. IEEE Computer Society Conference on Computer. Vis. Pattern Recognit. 2001, 1, 1034-1040.

55. Shao, D.Q.; Liu, T.; Wang, W.N.; Li, Z.Z. Construction of Traffic Accident Scenes Model Based on the Theory of Regional Disaster System. Geomat. Spat. Infor. Technol. 2018, 41, 34-38.

56. Yuan, Y.; Shao, C.; Cao, Z.; Chen, W.; Yin, A.; Yue, H.; Xie, B. Urban Rail Transit Passenger Flow Forecasting Method Based on the Coupling of Artificial Fish Swarm and Improved Particle Swarm Optimization Algorithms. Sustainability 2019, 11, 7230. [CrossRef]

57. Lu, J.; Ma, X.; Xing, Y. Risk factors affecting the severity of disruptions in metro operation in Shanghai, 2013-2016. J. Transp. Saf. Secur. 2019, 1-24. [CrossRef] 
58. Zarboutis, N.; Marmaras, N. Searching efficient plans for emergency rescue through simulation: The case of a metro fire. Cogn. Technol. Work. 2004, 6, 117-126. [CrossRef]

59. Yu, J.; Ji, Y.; Gao, L.; Gao, Q. Optimization of Metro Passenger Organizing of Alighting and Boarding Processes: Simulated Evidence from the Metro Station in Nanjing, China. Sustainability 2019, 11, 3682. [CrossRef]

60. Liu, M.; Zhao, L.D. An integrated and dynamic optimization model for the multi-level emergency logistics network in anti-bioterrorism system. Int. J. Sys. Sci. 2011, 9, 1-15.

61. Li, X.J. Analysis on the Safety risk of Subway Operation. J. Eng. Manag. 2017, 31, 83-88. [CrossRef]

62. Sheng, Y.; Sun, Q.Y.; Wang, Y.M. Emergency scenario evolution and extraction method of key elements. J. Saf. Sci. Technol. 2015, 11, 17-21.

63. Diab, E.; Shalaby, A. Metro transit system resilience: Understanding the impacts of outdoor tracks and weather conditions on metro system interruptions. Int. J. Sustain. Transp. 2019, 1-14. [CrossRef]

64. Gu, Y. Research on Storage and Dispatch of Regional Emergency Resources for the Significant Emergent Events. Doctor's Thesis, Wuhan University of Technology, Wuhan, China, 2009.

65. Sun, M.; Pan, Y. Multi-resource emergency scheduling based on complex networks. Oper. Res. Manag. Sci. 2009, 6, 164-169.

66. Yu, Y.Y.; Chi, H.; Qi, M.L.; Pan, B.C. Modeling and algorithm of resource layout evaluation and adjustment in emergency management. Sys. Eng. 2008, 1, 75-80.

67. Yuan, Y.; Wang, D.F. Route selection model in emergency evacuation under real time effect of disaster extension. J. Syst. Simul. 2008, 20, 1563-1566. [CrossRef]

68. Xu, B.K. An improved weighted summation algorithm for solving multi objective optimization problems. Master's Thesis, Xi'an University of Electronic Science and Technology, Xi'an, China, 2010.

69. Kennedy, J.; Eberhart, R.C.; Shi, Y. Swarm Intelligence; Elsevier: Amsterdam, The Netherlands, 2001.

70. Dominguez, M.; Fernandez-Cardador, A.; Cucala, A.; Gonsalves, T.; Fernández-Rodríguez, A. Multi objective particle swarm optimization algorithm for the design of efficient ATO speed profiles in metro lines. Eng. Appl. Artif. Intell. 2014, 29, 43-53. [CrossRef]

71. Gao, H.B. Research on Particle Swarm Optimization and its Several Applications in Engineering. Master's Thesis, Huazhong University of Science and Technology, Wuhan, China, 2004.

72. Hu, X.; Shi, Y.; Eberhart, R. Recent advances in particle swarm. Proceedings of the 2004 Congress on Evolutionary Computation. Evol. Comput. 2004, 90-97. [CrossRef]

73. Liu, D. Research on Particles Swarm Optimization and Its Engineering Application. Doctor's Thesis, Southwest Jiaotong University, Chengdu, China, 2013.

74. Li, T.G. Particle Swarm Optimization Based on Deb's Feasibility Rule for Optimal Design of Hydraulic Cylinder. Hydraul. Pneum. 2015, 7, 55-59.

75. Li, M.L.; Dai, C.J.; Liu, C.S. Adaptive Particle Swarm Optimization for Bilevel Programming Problem. Infor. Technol. Infor. 2014, 1, 94-96.

76. Al Moubayed, N.; Petrovski, A.; McCall, J. D 2 MOPSO: MOPSO Based on Decomposition and Dominance with Archiving Using Crowding Distance in Objective and Solution Spaces. Evol. Comput. 2014, 22, 47-77. [CrossRef] [PubMed]

(C) 2020 by the authors. Licensee MDPI, Basel, Switzerland. This article is an open access article distributed under the terms and conditions of the Creative Commons Attribution (CC BY) license (http://creativecommons.org/licenses/by/4.0/). 